\title{
Novel method for determination of heterocyclic compounds and their impact in brewing technology
}

\author{
Jana Olšovská, Karel Štěrba, Martin Slabý, Tomáš Vrzal \\ Research Institute of Brewing and Malting, Prague, \\ Lípová 511/15, 12000 Prague 2, Czech Republic \\ * corresponding author: olsovska@beerresearch.cz
}

\begin{abstract}
A new simultaneous method for determination of 16 heterocyclic compounds using SPE sample preparation and GC-MS determination was developed regarding increasing interest of the role of sensory active compounds in beer. LiChrolut ${ }^{\circledR}$ EN SPE columns proved to be optimal for both, a mixture of analytes with a different polarity and such complicated matrix as beer. Recoveries of individual analytes are about $100 \%$ except for three compounds (2-methylpyridine about $30 \%$, maltol and furaneol about $50 \%$ ); repeatability, uncertainty and LOQ are satisfactory for the method application. The method was used for monitoring of heterocyclic compounds formation during roasting, mashing, hop boiling and fermentation. To summarize, during roasting of malt, the concentration of oxygen heterocycle compounds $(\mathrm{OHC}$ ) increases more rapidly in comparison with nitrogen heterocycles compounds (NHC) till a critical point where $\mathrm{OHC}$ starts to decrease and $\mathrm{NHC}$ starts to be formed sharper (with the exception of 2-acetylpyrrole which is similar to $\mathrm{OHC}$ ). Finally, the total concentration of $\mathrm{NHC}$ during fermentation rapidly decreases whilst the $\mathrm{OHC}$ concentration is influenced by many factors, e.g., fermentation conditions and yeast strain.
\end{abstract}

Key words: heterocyclic compounds, pyrazines, furanones, malt, beer, solid phase extraction, GC-MS

\section{Introduction}

Organoleptic character of beer is influenced by various well-known compounds. However, there are still sensorially active compounds in beer, such as heterocyclic compounds (HC) which are not well described in literature yet. Moreover, published information is often not actual neither consistent.

The formation of HC is caused by a generally known Maillard reaction, which was firstly reported by Louis-Camille Maillard (1878-1936) in 1912 (Nursten, 2005). This process, also known as nonenzymatic browning, is based on a reaction between reducing sugars and proteins by the impact of heat (Bastos et al., 2012; Van Boekel, 1998). Recently, the reaction mechanisms responsible for formation of melanoidins involving active methylenes with heterocyclic structure and the structural characterization of the resulting products were published (Kanzler et al., 2019).
In case of brewing technology, Maillard reactions take place mostly in malt production, however, formation of Maillard reaction in beer and its intermediates was also published (Briggs et al., 2004; Miedaner 1986).

In general, alkyl-, hydroxy- and oxo-derivatives of 5- or 6-membered ring of HC with one or more heteroatoms (nitrogen, oxygen and sulphur) are the most important HC in beer (Briggs et al., 2004). The structures of typical nitrogen-containing (NHC) and oxygen-containing (OHC) HC representatives are given in Figure 1. The aroma of individual HC studied in this article is given in Table 1.

The theme of HC in malt, especially in dark and special malt, is relatively well studied and described. A pioneer GC-MS study published in 1978 described twenty-three basic $\mathrm{HC}$ that were identified in an extract from roasted barley. The author did not publish the concentra- 
tions of the identified substances but only their relative abundance (Harding et al., 1978).

A study of Forster et al. (1998) revealed a difference between a composition of black malt and dark malt with the colour of 29 and 1000 EBC units, respectively. Black malt had a different flavour composition in contrast to dark malt which resulted in dark beers with little malt flavour and lower flavour stability. High concentration of pyrazines found in black malt showed a correlation with the intensity of a burnt flavour.

Coghe et al. (2004) studied a flavour produced by dark special malts using analysis of wort samples brewed with different malts. Analyses were performed by GC-MS, sensory analyses were conducted by 12 trained assessors. They found that with an increasing wort colour, the intensity of bitter and burnt flavours also increases whereas sweet and husky flavour decreases. As expected, Maillard compounds increased with an increasing wort colour. However, not all Maillard reaction products evolved to the same extent.

Three classes of a roasted product (roasted barley, crystal malt and black malt) were analysed for a moisture content, colour and flavour volatiles by GC-MS in a study of Yahya et al (2014). In spite of having distinct flavour characteristics, the three products contained many common compounds. Besides, the effect of water sprays during roasting on decrease of pyrrole was found. The study highlights rapid changes in colour and particularly in flavour which occur at the end of roasting and onwards to the cooling floor.

In contrary to the malt matrix, there are very few studies about HC in beer. Pickett et al. (1976) published a study revealing differences between lagers and ales. The authors claimed that ales have a higher amount of certain heterocyclic compounds (2-acetylfuran, 5-methylfurfural, and 5-methyl-2-thiophenecarboxaldehyde).

Buiatti et al. (1997) published a GC-MS method with liquid-liquid extraction for the determination of some flavour compounds (furanones, derivative from maltol) in beer originating from barley malt. According to the authors, furanones presented in beer originated from caramel malt.

Viro (1984) compared a profile of HC in whiskey and beer using GC-FID. Pyridines, pyrazines, and thiazoles were identified in both beverages. In addition, pyrroles were detected in beer and quinolines in whisky. The concentration of found $\mathrm{HC}$ in beer was ranging between 0.2 to $6.5 \mu \mathrm{g} / \mathrm{L}$. The concentration of particular HC in whiskey was 5 to 10 times higher.

The origin of HC, 4-hydroxy-2,5-dimethyl-3(2H)-furanone (DMF), 4-hydroxy-2(or 5)-ethyl-5(or 2)-methyl-3(2H) -furanone(HEMF) and 5-methyl-4-hydroxy-3(2H)-furanone (MHF) during fermentation was described by Sakuma et al. (1996). The caramel-like sweet flavour and aroma were assigned to these substances using GC-O (gas chromatography-olfactometry) and combined GC-MS. The concentration of HEMF, HDMF and maltol ranged from 6 to 40, from 100 to 500 and from 300 to $600 \mu \mathrm{g} / \mathrm{L}$, respectively, in experimental beers. The flavour threshold of HEMF, HDMF and maltol was estimated by their panel as 700, 300 and $60 \mu \mathrm{g} / \mathrm{L}$, respectively.

More than 90 flavour components were described upon sniffing of the GC eluate in lager-type beer brewed from a mixture of partially dried green malt and extruded green malt (9:1). In all beer samples several unidentified components were described as giving a "roasted", "burnt", "bread crust" or "biscuit" odour. According to the authors, these odour characteristics probably derive from the alkylpyrazines presence. Positively identified pyrazines were found only in the "extruded" beer, namely methylpyrazine and 2,5 (and/or-2,6)-dimethylpyrazine (Fors et al., 1987).

Flavour active 4-hydroxyfuranones, maltol, furaneol and homofuraneol were analysed at each step of production in laboratory beers and samples. The effects of the length and temperature of mashing, length of boiling, rate of cooling the wort and grist composition on 4-hydroxyfuranone content in wort and subsequent beer were investigated. The fermentation temperature and use of the stabilizing agents, PVPP and Lucilite PC5, on the 4-hydroxyfuranone content of the beer were also investigated. The grist composition, rate at which the boiled wort is cooled and fermentation temperature were found as the most important factors. According to the authors, fermentation has a major effect on the final furanone content as yeast produces both, furaneol and homofuraneol. They suggested malt levels of precursor compounds may be more important than quantities of furanones found in malt in determining the final furanone content of beer (Mackie et al., 2002). The concentration of maltol and furaneol in final beer samples ranged in hundreds $\mu \mathrm{g} / \mathrm{L}$ depending on adjunct, fermentation temperature, or various stabilizing agents used.

For the first time, two OHC, sotolon and abhexon, causing nutty and curry flavour, respectively, and also two aspirane oxidation-derived products, dihydrodehydro- $\beta$-ionone and 4-hydroxy-7,8-dihydro- $\beta$-ionone, were determined in Gueuze beer by GC-MS and GC-0 method in 2012 (Scholtes et al., 2012). These compounds have been recently identified in oxidative wines such as Jura Flor-Sherry and Sauternes wines.

All above described studies are more application-oriented, whilst the study of Hérent et al. (1998) is methodical. They studied structural properties of pyrazines and thiazoles that contribute to roasted flavours of cooked foods, such as bread, coffee, meat, and to the malt-like flavours of beer. These odours of the "nutty class" are gener- 
ally displayed by short-chain polyalkyl heterocycles and by acetyl- and methoxy-substituted analogues (Shibamoto, 1986; Fors et al., 1987). Due to their low sensory threshold, quantification of such compounds is a challenge for food analysts. Therefore, the study focuses on an optimized extraction method including steam-vacuum distillation with subsequent liquid-liquid extraction followed by gas chromatography-nitrogen-phosphorus detector analysis enabling to quantify $50 \mathrm{ppt}$ of such heterocycles in model aqueous and water/ethanol solution (Hérent et al., 1998).
The aim of the study was (i) to collect information on HC in beer published so far including a method of extraction and determination, monitoring of $\mathrm{HC}$ origin of NHC and OHC in the sequence of "malt-sweet wortwort-beer", (ii) to improve an extraction method which would have sufficient recovery and repeatability for all studied HC determined simultaneously, (iii) to validate the method of HC determination, (iv) to evaluate HC profiles in malts with an increasing colour, and (v) to study HC distribution in the sequence of "sweet wortwort-beer".

Figure 1 Structures of selected $\mathrm{NHC}$ and $\mathrm{OHC}$ compounds<smiles>c1cc[nH]c1</smiles>

pyrrols<smiles>c1cnccn1</smiles>

pyrazines<smiles>c1ccncc1</smiles>

pyridines<smiles>c1cscn1</smiles>

thiazols<smiles>Cc1occc(=O)c1O</smiles>

maltol<smiles>CC1=C(O)C(=O)C(C)O1</smiles>

furaneol<smiles>CC1=C(O)C(=O)OC1C</smiles>

sotolon<smiles>CCC1OC(C)=C(O)C1=O</smiles>

homofuraneol<smiles>CCC1OC(=O)C(O)=C1C</smiles>

abhexon

Table 1 Aroma description of heterocyclic compounds

\begin{tabular}{|c|l|}
\hline \multicolumn{1}{|c|}{ Compounds } & \multicolumn{1}{|c|}{ Aroma } \\
\hline maltol & sweet, candyfloss, caramel, fruits, nuts, sour, astringent, bitter, oily \\
\hline furaneol & strawberry, caramel, candyfloss, sweet, brown sugar \\
\hline homofuraneol & sweet, candyfloss, bread crust, sugar, roasted coffee, light soy sauce \\
\hline sotolon & $\begin{array}{l}\text { fenugreek, curry leaves, maple syrup, caramel, slightly burnt sugar, nuts, lovage, molasses, dried } \\
\text { mushrooms, tobacco }\end{array}$ \\
\hline abhexon & fenugreek, curry leaves, nuts, sweet fruits, caramel, brown sugar, maple syrup \\
\hline 2-Methylpyridine & coffee, soy sauce, sweet, astringent, hazelnuts \\
\hline 2-Methylpyrazine & coffee, fresh bread, fried meat, nuts, cocoa, peanuts, mouldy \\
\hline 3-Methylpyridine & earthy, fresh, grass, hazelnuts, fish \\
\hline 2,5-Dimethylpyrazine & roasted nuts, peanuts, fried meat, earthy, mouldy, coffee, cocoa, woody \\
\hline 2,6-Dimethylpyrazine & roasted nuts, peanuts, fried meat, earthy, mouldy, coffee, cocoa, woody \\
\hline 2,3-Dimethylpyrazine & roasted nuts, peanuts, fried meat, earthy, mouldy, coffee, cocoa, woody \\
\hline 2,3,5-Trimethylpyrazine & roasted nuts, peanuts, fried meat, earthy, mouldy, coffee, cocoa, woody \\
\hline 2-Acetylpyridine & tobacco, popcorn, higher fatty acids \\
\hline 2-Acetylthiazole & nuts, popcorn, roasted, sulphur \\
\hline 3-Acetylpyridine & roasted nuts, popcorn, maize, sawdust \\
\hline 2-Acetylpyrrole & mouldy, leathery, cherry, cherry liqueur, walnuts, cinnamon \\
\hline $\begin{array}{l}\text { Pubchem (a); Pubchem (b); Pubchem (c); Dunkel et al., 2009; Korhoňová et al., 2009; Ishizaki et al., 2005; Mahajan et al., 2004; Buttery } \\
\text { et al., 1995; Beal et al., 1994; Pittet et al., 1970. }\end{array}$ \\
\hline
\end{tabular}




\section{Materials and methods}

\section{Chemicals}

Hexane ( $\geq 99 \%)$, dichloromethane $(\geq 99.9 \%$ ) were purchased from Honeywell. 3-Hydroxy-2-methyl-4Hpyran-4-one (maltol, $\geq 99 \%$ ), 4-hydroxy-2,5-dimethyl-3(2H)-furanone (furaneol, $\geq 99 \%$ ), 2-ethyl-4-hydroxy-5-methyl-3(2H)-furanone (homofuraneol, 96\%), 4,5-dimethyl-3-hydroxy-2,5-dihydrofuran-2-one (sotolon, $\geq 97 \%$ ), 5-ethyl-3-hydroxy-4-methyl-2(5H)-furanone (abhexon, 97\%), 2-methylpyridine ( $\geq 98 \%$ ), 3-methylpyridine ( $\geq 98 \%$ ), 2-methylpyrazine ( $\geq 98 \%$ ), 2,3-dimethylpyrazine ( $\geq 99 \%$ ), 2,5-dimethylpyrazine ( $\geq 98 \%$ ), 2,6-dimethylpyrazine (98\%), 2,3,5-trimethylpyrazine (99\%), 2-acetylpyridine (98\%), 3-acetylpyridine ( $\geq 99 \%), 2$-acetylthiazole (99\%), 2-acetylpyrrole (99\%), and 5-ethyl-2-methylpyridine ( $\geq 96 \%$ ) were purchased from Merck.

\section{Malt samples}

Profiles of HC were studied in pale Pilsner malt \#1 (colour of 4 EBC), pale caramel malt \#2 (72 EBC) and malt \#3 (125 EBC units), dark caramel malt \# 4 (182 EBC) malt \#5 (382 EBC) and finally colouring malt \#6 (1400 EBC). The colour of malt samples was determined by EBC 4.7.1 method.

Tested malts were obtained from the malthouse Litovel of SLADOVNY SOUFFLET CR, a.s. The preparation procedure of caramel and colouring malts was very similar. In the first phase, green malt was poured into a preheated drum of a roaster, which cooled down and immediately began to heat up to the saccharification temperature. This step was the most important as grains have to be perfectly saccharified before roasting to achieve good caramelization. Different types of caramel malt differ in the roasting temperature and length. The roasting phase consists of several steps, where the last phase when the power of burners is reduced is the most important to achieve the required colour.

In general, the total roasting time on $1 \mathrm{t}$ dose was about $3: 20 \mathrm{~h}$ for malt with colour of 100-120 EBC, $3: 50 \mathrm{~h}$ for malt with colour of 200-220 EBC and 4:20 h for higher colour than 350 EBC. The caramelization temperature of caramel malts was ranging from 140 to $160{ }^{\circ} \mathrm{C}$; specifically, it depended on requirements of a roaster and grain parameters. The temperature of dark caramel caramelization was ranging from 170 to $180^{\circ} \mathrm{C}$, coloured malt was prepared at $220-230^{\circ} \mathrm{C}$. The caramel malt \#2 (72 EBC) is very light caramel malt where the roasting temperature was kept for a shorter time to reach the target colour and rapid cooling was performed so that the malt did not increase the colour during cooling. The caramel malts with the colour of
100-120 EBC has the same recipe as caramel malts with the colour of $140-160 \mathrm{EBC}$, the difference is only in the last stage of roasting.

Typically, the temperatures and durations of individual roasting phases slightly vary from batch to batch depending on the weather and quality of green malt (humidity, variety, protein content, degree of soaking, degree of decomposition, etc.)

The EBC 4.5.1. congress wort method was used to convert HC from malt to solution. For this purpose, the tested caramel and colouring malts were mixed with malt \#1 in ratio 1:1. The final congress mashes were extracted using SPE (see above) and analysed by GC-MS. The final concentration of individual $\mathrm{HC}$ was calculated according to the mixing ratio.

\section{Beer samples - brewing technology}

HC profiles in sweet wort and respective wort and beer were determined in eight batches (1-8) prepared in a Kaspar-Schulz (Germany) research brewhouse with maximum capacity of $250 \mathrm{~L}$ using the same brewing recipe. Every batch was prepared from different pale pilsner malt (see Table 2). An exception was made with batches 3 and 4 that were not hopped. Every batch was prepared from different pale pilsner malt (see Table 2).

The malt varieties Laudis 550, Overture, Francin, Bojos and Monus were malted in the malthouse of Pilsner Urquell brewery and SLADOVNY SOUFFLET CR, a.s. (see Table 2).

The grist composition of each batch was $33 \mathrm{~kg}$ of malt (extract-dry basis $81.5 \%$ ). The volume of cold wort was approx. 185 L. Double decoction mashing was used for all batches. The mash temperature was $37{ }^{\circ} \mathrm{C}$ and the rest of $10 \mathrm{~min}$, followed by heating to $52^{\circ} \mathrm{C}$ with the temperature gradient of $0.8{ }^{\circ} \mathrm{C} / \mathrm{min}$ and the rest of $5 \mathrm{~min}$. First partmash was taken, followed by heating to $63{ }^{\circ} \mathrm{C}$ at the temperature gradient of $0.8{ }^{\circ} \mathrm{C} / \mathrm{min}$ and the rest of $15 \mathrm{~min}$, temperature of the next heating was $72{ }^{\circ} \mathrm{C}$ at gradient of $1.3^{\circ} \mathrm{C} / \mathrm{min}$ and rest for ideal saccharification. Duration of the following heating to boil was $20 \mathrm{~min}$. After returning the first partmash, the temperature of brew was $63{ }^{\circ} \mathrm{C}$ and the second partmash was taken. It was heated to $72{ }^{\circ} \mathrm{C}$ at gradient of $1.3^{\circ} \mathrm{C} / \mathrm{min}$ and rested for ideal saccharification. Last heating to boil lasted $15 \mathrm{~min}$, the temperature after returning was $77^{\circ} \mathrm{C}$.

The 90 min hop boiling with 3 doses was used. Final bitterness of beer was 30 IBU. Firstly, $50 \%$ of total alpha acids was added using $\mathrm{CO}_{2}$ extract (Hercules variety) at the beginning of boiling. Secondly, SAAZ hop pellets equal to $35 \%$ of total alpha acids were added after 35 minutes. Thirdly, SAAZ hop pellets equal to $15 \%$ of total alpha acids were added before the end of boiling. 
All eight batches were fermented identically by RIBM 95 yeast in cylinder conical tank from PRODUKT CZ (Czech Republic). The fermentation temperature and dose were $10{ }^{\circ} \mathrm{C}$ and $2 \mathrm{~g} / \mathrm{L}$, respectively, which corresponds with cells amount about 17-19 million. The aeration of wort was set at $8 \pm 1 \mathrm{mg} \mathrm{O}_{2} / \mathrm{L}$. The maximal temperature of fermentation was $12{ }^{\circ} \mathrm{C}$, the length of fermentation was about 5 days and was controlled by a limit of diacetyl concentration of $150 \mu \mathrm{g} / \mathrm{L}$. Maturation, in the second step, took place in a lager cellar at $2.0^{\circ} \mathrm{C} \pm 0.5^{\circ} \mathrm{C}$ for 21 days.

The final beer was finally filtered on a plate filter with S10N filter plates (Hobra Školník, Broumov) and packed into bottles without the oxygen access.

\section{Sample preparation - distillation method}

The sample was prepared according to the modified methodology MEBAK 2.23.6 "Determination of steam-volatile aroma compounds in beer". One hundred millilitres of beer with the addition of $500 \mu \mathrm{L}$ of internal standard (5-ethyl-2-methylpyridine, $300 \mathrm{mg} / \mathrm{L}$ ) was distilled off with steam on a Büchi distillation apparatus. The distillate was collected in a $250 \mathrm{~mL}$ volumetric flask containing $10 \mathrm{~mL}$ of a $1: 1 \mathrm{v} / \mathrm{v}$ hexane-dichloromethane mixture placed in an ice-water bath. After the completion of the distillation, the sample was shaken on an orbital shaker (250 rpm) for $1 \mathrm{~h}$. After shaking, the sample was placed in a refrigerator for at least $1 \mathrm{~h}$ to separate phases. The organic layer was collected for analysis.

\section{Sample preparation - SPE method}

The beer sample was degassed at an ultrasonic bath. SPE column LiChrolut@ EN $500 \mathrm{mg}$ was conditioned with $5 \mathrm{~mL}$ of methanol followed by $5 \mathrm{~mL}$ of water. Fifty millilitres of beer with the addition of $250 \mu \mathrm{L}$ of an internal standard (2-ethyl-5-methylpyridine) at a concentration of $300 \mathrm{mg} / \mathrm{L}$ was loaded on the column. Subsequently, the column was washed with $5 \mathrm{~mL}$ of water and then dried by the flow of nitrogen. The HC were eluted by $5 \mathrm{~mL}$ of ethyl acetate. The extract was then concentrated by the flow of nitrogen to the final volume of $1 \mathrm{~mL}$.

Strata $\mathrm{X} \circledast$ and LiChrolut ${ }^{\circledR}$ RP-18 columns were also tested (see Results and Discussion, Table 3).

\section{GC analysis}

The determination was performed on a Thermo Ultra gas chromatograph with a DSQ II mass spectrometer. The chromatographic column used was TG-WAXMS (Thermo), $30 \mathrm{~m}$ length, $0.25 \mathrm{~mm}$ inner diameter and $0.25 \mu \mathrm{m}$ film thickness. Temperature gradient was as follows:
$40{ }^{\circ} \mathrm{C}(2 \mathrm{~min})-10{ }^{\circ} \mathrm{C} / \mathrm{min}-150{ }^{\circ} \mathrm{C}(0 \mathrm{~min})-2{ }^{\circ} \mathrm{C} / \mathrm{min}-$ $160^{\circ} \mathrm{C}(0 \mathrm{~min})-20^{\circ} \mathrm{C} / \mathrm{min}-200^{\circ} \mathrm{C}(0 \mathrm{~min})-40^{\circ} \mathrm{C} / \mathrm{min}$ $-230^{\circ} \mathrm{C}$ (5 min). The carrier gas flow (He, purity 5.0) was $1.2 \mathrm{~mL} / \mathrm{min}$. One microliter of the sample was injected in a splitless mode, $1 \mathrm{~min}$ after the injection the split was opened at the flow rate of $50 \mathrm{~mL} / \mathrm{min}$. The temperature of the injector and transfer line to the mass spectrometer was $250^{\circ} \mathrm{C}$. The measuring mode was set to SIM, selected ions for each compound are listed in Table 4. The identification and quantification of HC was performed by the software Xcalibur 2.1 (Thermo Scientific). All samples were prepared in duplicate.

\section{Method validation}

The basic validation parameters as the limit of detection (LOD), limit of quantification (LOQ), uncertainty, repeatability and recovery were determined. LOD and LOQ were determined as 3.3 and 10 multiples, respectively, of standard deviation of the blank which was measured 10 times.

Uncertainty and repeatability were calculated as 2 and 2.8 multiples, respectively, of standard relative deviation of eight replicates.

Recoveries of particular HC were evaluated using an addition of a relevant compound to a standard sample of beer. The concentrations of added NHC, OHC and acetylpyrrol were 50, 4000 and $500 \mu \mathrm{g} / \mathrm{l}$, respectively. All samples were prepared in quadruplicate.

\section{Results and discussion}

\section{Method optimization}

Basic requirements for the method of HC determination within its optimization were sufficient recovery, uncertainty, repeatability and LOQ of all components determined simultaneously. Due to wide structural variability of these substances, it was very difficult to satisfy these requirements.

Table 2 List of beer batches with relating malt variety and malthouse origin

\begin{tabular}{|c|c|c|}
\hline Batch No. & Malt variety/Malthouse & Hopped \\
\hline 1 & Laudis 550/Soufflet & YES \\
\hline 2 & Overture/Soufflet & YES \\
\hline 3 & Laudis 550/Soufflet & YES \\
\hline 4 & Overture/Soufflet & NO \\
\hline 5 & Overture/PU & NO \\
\hline 6 & Francin/PU & YES \\
\hline 7 & Bojos/PU & YES \\
\hline 8 & LG Monus/Soufflet & YES \\
\hline
\end{tabular}


Table 3 Recoveries (\%) of HC - comparison of distillation and SPE preparation $(n=4)$

\begin{tabular}{|c|c|c|c|c|}
\hline \multirow[b]{2}{*}{ Compound } & \multirow[b]{2}{*}{ Distilation } & \multicolumn{3}{|c|}{ SPE } \\
\hline & & Strata $X ®$ & LiChrolut@ RP-18 & LiChrolut ${ }^{\circledR}$ EN \\
\hline 2-methylpyridine & 2 & 11 & 4 & 32 \\
\hline 2-methylpyrazine & 9 & 3 & 1 & 95 \\
\hline 3-methylpyridine & 129 & 32 & 89 & 97 \\
\hline 2,5-dimethylpyrazine & 26 & 15 & 1 & 112 \\
\hline 2,6-dimethylpyrazine & 16 & 11 & 1 & 115 \\
\hline 2,3-dimethylpyrazine & 19 & 14 & 1 & 115 \\
\hline 2,3,5-trimethylpyrazine & 71 & 52 & 1 & 130 \\
\hline 2-acetylpyridine & 34 & 23 & 6 & 107 \\
\hline 2-acetylthiazole & 73 & 41 & 77 & 108 \\
\hline 3-acetylpyridine & 128 & 51 & 42 & 120 \\
\hline 2-acetylpyrrole & 16 & 71 & 21 & 115 \\
\hline maltol & 1 & 6 & 2 & 59 \\
\hline furaneol & 4 & 12 & 3 & 50 \\
\hline homofuraneol & 48 & 148 & 48 & 130 \\
\hline sotolon & 856 & 17 & 86 & 77 \\
\hline abhexon & 131 & 4 & 4 & 135 \\
\hline
\end{tabular}

Due to low recovery of a steam distillation method, three different SPE sorbents were tested (see Table 3). As follows from Table 3, the most efficient SPE column for HC extraction is LiChrolut $\AA$ EN given the tested procedure. Recoveries of all tested HC significantly increased, even the recovery of NHC such as 2,5-dimethylpyrazine, 2,6-dimethylpyrazine and 2,3-dimethylpyrazine was nearly $100 \%$. Recovery of OHC also increased, namely maltol and furaneol were about $50 \%$ which is more than a tenfold increase compared to the original method. To the best of our knowledge, the SPE has not yet been used for extraction and preconcentration of HC in beer matrix.

Table 4 SIM ions used for MS analysis

\begin{tabular}{|c|c|c|c|}
\hline Compound & Retention time (min) & Qualifier (m/z) & Quantifier (m/z) \\
\hline 2-methylpyridine & 7.1 & $66,67,93,94,108$ & 93 \\
\hline 2-methylpyrazine & 7.8 & $66,67,93,94,108$ & 94 \\
\hline 3-methylpyridine & 8.2 & $66,67,93,94,108$ & 93 \\
\hline 2,5-dimethylpyrazine & 8.6 & $66,67,93,94,108$ & 108 \\
\hline 2,6-dimethylpyrazine & 8.7 & $66,67,93,94,108$ & 108 \\
\hline 2,3-dimethylpyrazine & 9.0 & $66,67,93,94,108$ & 108 \\
\hline 2,3,5-trimethylpyrazine & 9.7 & $79,106,112,121,122,127$ & 122 \\
\hline ISTD* & 9.9 & $79,106,112,121,122,127$ & 106,121 \\
\hline 2-acetylpyridine & 12.4 & $79,106,112,121,122,127$ & 121 \\
\hline 2-acetylthiazole & 12.9 & $79,106,112,121,122,127$ & 127 \\
\hline 3-acetylpyridine & 15.4 & $78,94,106,109,121$ & 121 \\
\hline 2-acetylpyrrole & 18.1 & $78,94,106,109,121$ & 94,109 \\
\hline maltol & 18.0 & $50-150$ & 126 \\
\hline furaneol & 19.1 & $50-150$ & 128 \\
\hline homofuraneol & 19.7 & $50-150$ & 142 \\
\hline sotolon & 21.0 & $83,107,122,126,128,142$ & 83,128 \\
\hline abhexon & 21.6 & $83,107,122,126,128,142$ & 142 \\
\hline
\end{tabular}

*ISTD = internal standard 
Determination of $\mathrm{HC}$ was performed in a SIM/scan mode and parameters, namely retention time, qualifier and quantifier ions $(\mathrm{m} / \mathrm{z})$ are listed in Table 4 .

Previously, Sakuma et al. (1996) and Mackie et al. (2002) used hexanol and decanol, respectively, as an internal standard. The extraction method according to Sakuma et al. (1996) was based on cooling of a beer sample in an ice bath, pouring onto Extrelut 3 and after 15-min extraction by methylene chloride. The residue was dissolved in hexanol/acetonitrile solution and then the internal standard was added. Furthermore, Mackie et al. (2002) saturated the sample with sodium chloride, shook it with methyl acetate for $10 \mathrm{~min}$ and centrifugated it. Then, they evaporated the organic layer to define volume and finally, added the internal standard.

Unusually, both authors added the internal standard only after extraction of HC from beer. It means that by adding a standard, they controlled only the recovery of the final MS method and not the whole method, including an extraction step. Unlike these methods, the internal standard in our method is added into a beer sample before the extraction step. Moreover, the internal standard, 2-ethyl-5-methylpyridine, has a similar structure as tested NHC and guarantees similar behaviour as HC during the SPE step. The concentration of 2-ethyl-5-methylpyridine in beer without the internal standard addition was verified and found as negligible (data not shown).

\section{Method validation}

Although quite many articles deal with the concentration of HC in some matrices, validation data are almost missing. The validation parameters of the final SPE method are listed in Table 5.

The most similar method was published by Ferreira et al. (2003), where they determined soloton, maltol and furaneol in wine. They also used SPE extraction with LiChrolut EN sorbent. Due to a different matrix and narrow spectrum of target compounds, they used different conditions for sample cleaning and elution (cleaning step pentane-dichloromethane 20:1 v/v, elution step - dichloromethane). The detection limits of the method ranged between 0.5 and $1.0 \mu \mathrm{g} / \mathrm{L}$ (Ferreira et al., 2003). A comparable LOD was achieved in our study for NHC, however, the reached LOD was ten times higher compared to OHC.

Study of Fan et al. (2007), where the authors characterized pyrazines in some Chinese liquors by liquid-liquid extraction with diethyl ether and HS-SPME followed by GC-FTD (flame thermionic detector) reported that LOD for most pyrazines was below $0.2 \mu \mathrm{g} / \mathrm{L}$ and the recovery of all studied pyrazines in synthetic liquor ranged from about 80 to $120 \%$ which corresponds with our results.

\section{Method application}

- Determination of HC in different types of malt

The profiles of $\mathrm{OHC}$ and NHC in the tested malts are given in Figure 2 and 3, respectively. It should be reminded that concentration of HC was determined in congress wort (see experimental section). The dependence of the

Table 5 Validation parameters of the final method

\begin{tabular}{|c|c|c|c|c|c|}
\hline Compound & Uncertainty (\%) & Recovery (\%) & Repeatability (\%) & LOD $(\mu \mathrm{g} / \mathrm{L})$ & LOQ ( $\mu \mathrm{g} / \mathrm{L})$ \\
\hline 2-methylpyridine & 21 & 32 & 29 & 1.34 & 4.05 \\
\hline 2-methylpyrazine & 8 & 95 & 11 & 0.25 & 0.76 \\
\hline 3-methylpyridine & 14 & 97 & 20 & 0.99 & 3.01 \\
\hline 2,5-dimethylpyrazine & 19 & 112 & 24 & 0.12 & 0.36 \\
\hline 2,6-dimethylpyrazine & 14 & 115 & 10 & 0.14 & 0.41 \\
\hline 2,3-dimethylpyrazine & 15 & 115 & 8 & 0.26 & 0.80 \\
\hline 2,3,5-trimethylpyrazine & 22 & 130 & 16 & 0.12 & 0.36 \\
\hline 2-acetylpyridine & 15 & 107 & 19 & 0.78 & 2.37 \\
\hline 2-acetylthiazole & 19 & 108 & 27 & 0.79 & 2.40 \\
\hline 3-acetylpyridine & 14 & 120 & 20 & 0.40 & 1.21 \\
\hline 2-acetylpyrrole & 23 & 115 & 17 & 1.42 & 4.31 \\
\hline Maltol & 14 & 59 & 15 & 65.1 & 197 \\
\hline Furaneol & 14 & 50 & 12 & 59.5 & 180 \\
\hline Homofuraneol & 31 & 130 & 30 & 77.8 & 236 \\
\hline Sotolon & 64 & 77 & 90 & 43.8 & 133 \\
\hline Abhexon & 38 & 135 & 54 & 28.6 & 86.7 \\
\hline
\end{tabular}


individual $\mathrm{HC}$ concentration on the increasing colour can be also indirectly considered as the dependence on the temperature and time of roasting which was previously studied by Vandecan et al. (2011). They observed the malt colour development (in EBC units) during the malt caramelization phase at different roasting temperatures ranging from 100 to $180{ }^{\circ} \mathrm{C}$. They found that the malt colour increased with the increasing temperature and time at temperatures ranging from 100 to $160{ }^{\circ} \mathrm{C}$ (Vandecan et al., 2011).

Comparing Figure 2 and 3, the course of the trend of formation of $\mathrm{OHC}$ and $\mathrm{NHC}$ on the malt colour is different. OHC content generally increases except for abhexone and maltol whose concentrations are maximal in the malt \#3 (125 EBC) and malt \#4 (382 EBC) with the concentration of about 1.25 and $7 \mathrm{mg} / \mathrm{L}$, respective-

Figure 2 Profile of $\mathrm{OHC}$ in tested congress wort of tested malts (concentration of some $\mathrm{HC}$ were divided by a constant to be comparable in one graph)

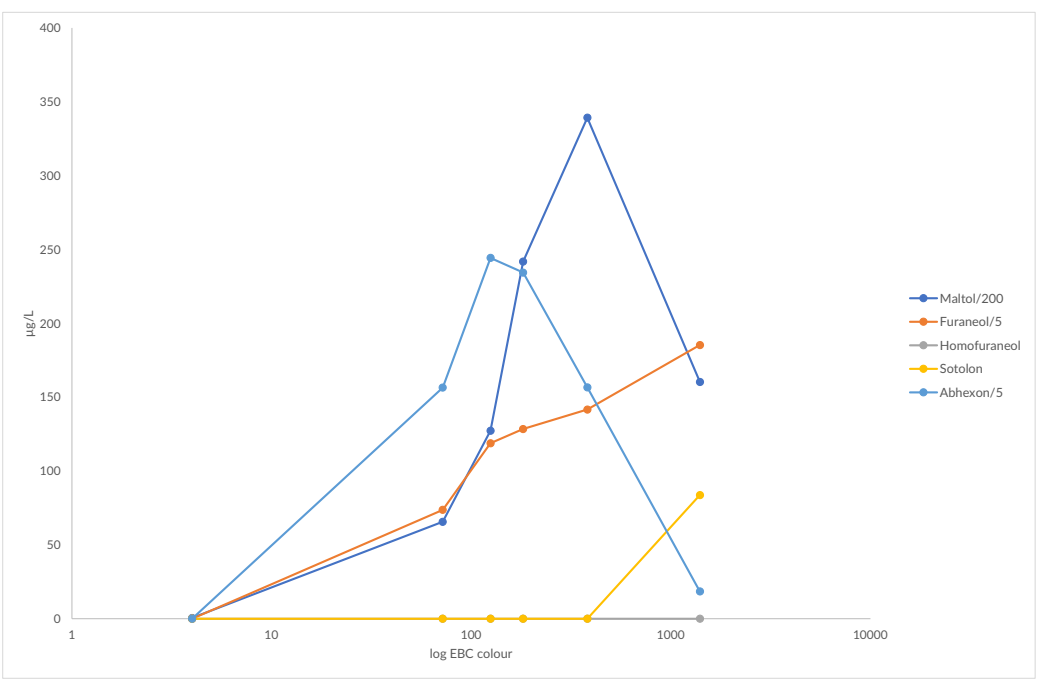

Figure 3 Profile of NHC in tested congress wort of tested malts (concentration of some $\mathrm{HC}$ were divided by a constant to be comparable in one graph)

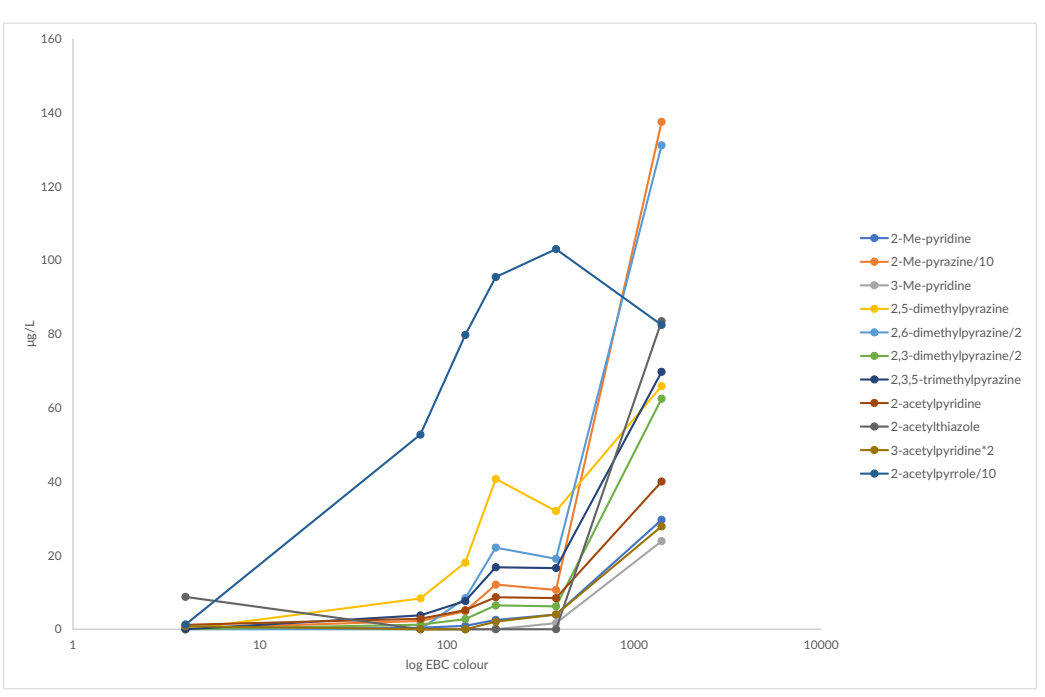

ly, then the concentration decreases. The final concentration of soloton and furaneol was 0.08 and $0.9 \mathrm{mg} / \mathrm{L}$, respectively.

The increase of NHC concentration during roasting is slower in comparison with OHC. NHC content increases slightly with a higher final curing temperature or decreases slightly at a higher temperature. Also, the final concentration of NHC is in general lower in comparison with $\mathrm{OHC}$, about 10 to 100 times. The exception is 2-acetylpyrrole which is the most abundant NHC with concentration of about $1 \mathrm{mg} / \mathrm{L}$ in the congress wort of malt \#5 (382 EBC). Whilst 2-acetylpyrrole decreases with a higher roasting temperature, the concentration of the other NHC such as 2-methylpyrazine and 2,6-dimethylpyrazine increases with the maximal concentration of 1.4 and $0.3 \mathrm{mg} / \mathrm{L}$, respectively. It should be noted that the decrease of 2-acetylpyrrole is within uncertainty of determination (see Table 5).

The trend of slight increasing of NHC concentration in caramel malts followed by their sharp increase in coloured malt is in accordance with a study of Forster et al. (1998). The authors determined the total pyrazines concentration in pale malt, dark malt with pale withering, dark malt with dark withering and black malt as $<0.05,0.4,0.5$ and $34.7 \mathrm{mg} / \mathrm{kg}$, respectively (Forster et al., 1998). Similarly, methylpyrazine and pyrazine dramatically increased in wort with colour of $880 \mathrm{EBC}$ units, compared to wort 5, 67, and 480 EBC units (Coghe et al., 2004).

To summarize it, our study of HC profiles in different types of malt is in accordance with previously published findings but, moreover, firstly describes behaviour of $\mathrm{OHC}$ during caramelization and roasting. Also a list of NHC is wider, it contents not only pyrazines but representatives of pyrrols and pyridines, too. 
Method application

- Determination of HC during brewing technology

Distribution of HC during brewing technology is described in Figures 4, 5, 6 and 7. Undoubtedly, the first conclusion from these results is the fact that the total concentration of NHC during fermentation significantly decreases, whilst the trend of $\mathrm{OHC}$ is not so unambiguous. It follows from our subsequent experiment where the rate of HC concentration change during fermentation is influenced by the yeast strain used. Detailed data will be published in a prepared study regarding a sensomic study of lagers fermented by different yeast strains. Likewise, Sakuma et al. (1996) confirmed the influence of yeast strain on concentration of formed furaneol during fermentation.

The most abundant component of the monitored NHC was 2-acetylthiazole whose profile copies well the total amount of NHC in sweet wort and wort (Figure 5). During fermentation, the 2-acetylthiazole content as well as the total NHC content significantly decrease. According to authors knowledge, this finding has not been published yet.

The total $\mathrm{OHC}$ content increases during a hop boiling step, with the exception of non-hopped batches 3 and 4 where the OHC content increases during fermentation (Figure 6). Hence, it could be concluded that addition hop during wort boiling may potentially have a crucial role in $\mathrm{OHC}$ formation during beer production. Interesting differences among individual batches and also in the sequence of "sweet wort-wortbeer" were observed for the furaneol profile (Figure 7). Since the malts type and brewing technology were the same, an explanation is offered that the final concentration of furaneol depends on the malt variety and/or malting technology. Such possible explanation is in accordance with a study of Mackie et al. (2002). They found that the degree of heating during kilning is not reflected only in the concentration of furaneol and maltol in the malt but also in the levels of precursors suitable for conversion to furanones by heating during brewhouse operations and by yeast fermentation. In addition, also the fermentation process, yeast strains and their conditions could potentially influence the final concentration of $\mathrm{OHC}$.

To summarize, higher alcohols, esters, and shortchain fatty acids are not the only important substances originated by yeast, but $\mathrm{OHC}$ are also important sensorially active compounds produced during fermentation.

\section{Conclusion}

Heterocyclic compounds are one of the little explored groups of substances in beer. The newly developed and optimized method of simultaneous determination of 
Figure 6 Distribution of the total amount of $\mathrm{OHC}$ during brewing process in batches 1-8

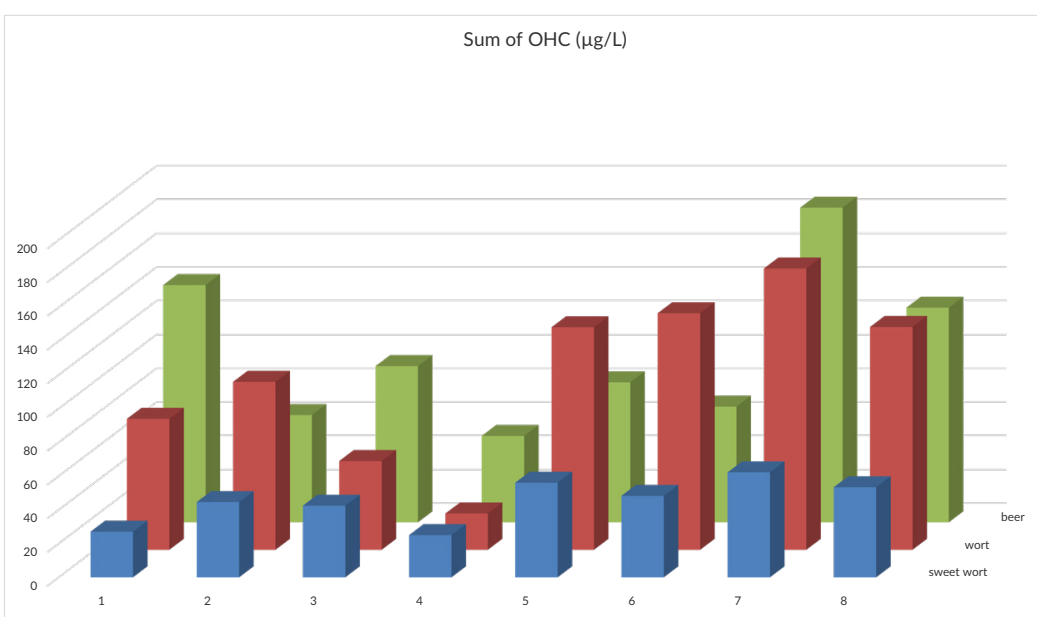

Figure 7 Distribution of furaneol during brewing process in batches 1-8

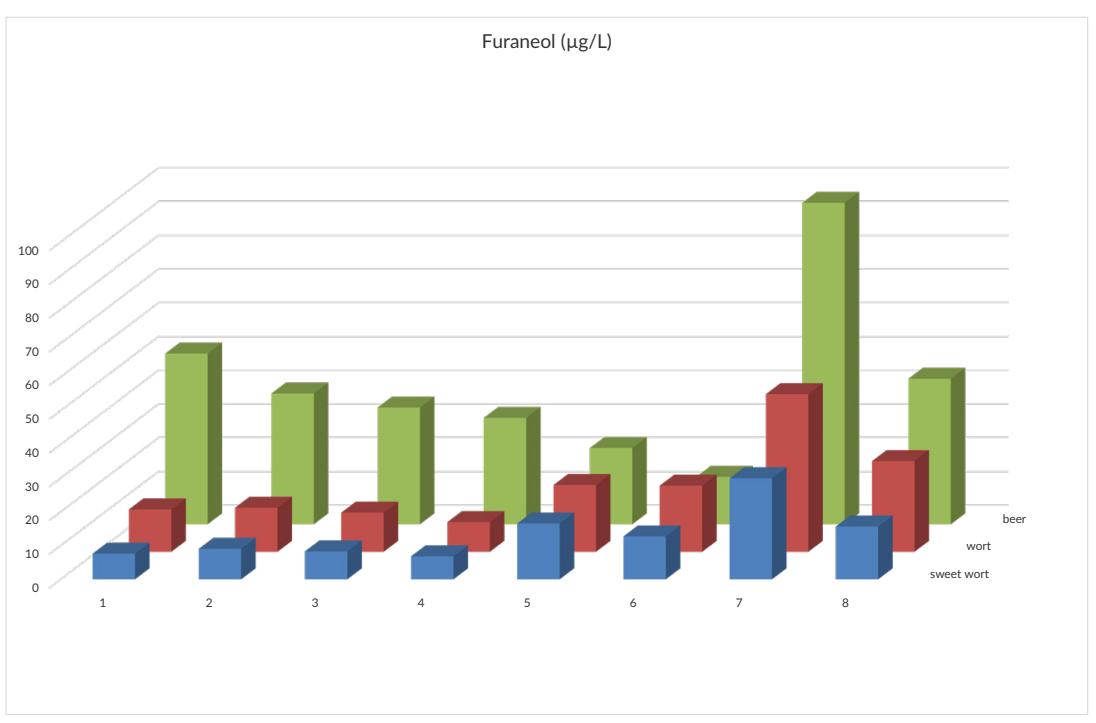

16 compounds in wort and beer uses the solid phase extraction for sample preparation and preconcentration. Although the method involves substances of a different polarity, the method parameters such as repeatability, recovery, uncertainty and LOQ are quite satisfactory.

Further, there was concluded that the formation of $\mathrm{OHC}$ and NHC considering increasing malt colour is different. In general, $\mathrm{OHC}$ content increases during fermentation relatively sharply till the maximum in comparison with NHC. Only the 2-acetylpyrrole is an exception, its behaviour during roasting is very similar to $\mathrm{OHC}$.

Finally, monitoring of $\mathrm{HC}$ within brewing in the sequence of "sweet wort-wort-beer" was evaluated. In summary, the total concentration of NHC during fermentation decreases whilst the $\mathrm{OHC}$ concentration is influenced by many factors, e.g., fermentation conditions and the yeast strain.

The newly developed method will be used in our following studies regarding sensomic profiling of beer.

\section{Acknowledgments}

The article was supported by the Ministry of Agriculture of the Czech Republic, within Institutional Support MZE-R01918. The authors thank to Ing. Roman Novotný from SLADOVNY SOUFFLET CR, a.s. for providing malt samples and detailed information about special malt technology.

\section{References}

Bastos, D.M., Monaro, É., Siguemoto, É., Séfora, M. (2012). Maillard reaction products in processed food: pros and cons. In: Valdez, B. (ed.) Food Industrial Processes - Methods and Equipment, IntechOpen, pp. 281-300. ISBN 978-953-307-905-9, https://doi.org/10.5772/31925 Beal, A.D., Mottram, D.S. (1994). Compounds contributing to the characteristic aroma of malted barley. Journal of Agricultural and Food Chemistry, 42(12), 2880-2884. https://doi.org/10.1021/jf00048a043 Briggs, D.E., Boulton, C.A., Bookes, P.A., Stevens, R. (2004). Brewing Science and Practice. Woodhead Publishing Limited, Abington Hall, Abington, Cambridge. 311-319. ISBN 1-85573-490-7

Buiatti, S., Battistutta, F., Celotti, E., Zironi, R. (1997). Evaluation of beer flavour compounds by liquid-liquid extraction and GC/MS analysis. MBAA Technical Quarterly, 34(4), 243-245.

Buttery, R.G., Takeoka, G.R., Ling, L.C. (1995). Furaneol: Odor Threshold and Importance to Tomato Aroma. Journal of Agricultural and Food Chemistry, 43(6), 1638-1640. https://doi.org/10.1021/jf00054a042

Coghe, S., Martens, E., D’Hollander, H., Dirinck, P.J., Delvaux, F.R. (2004). Sensory and instrumental flavour analysis of wort brewed with dark specialty malts. Journal of The Institute of Brewing, 110(2), 94-103. https://doi.org/10.1002/j.2050-0416.2004.tb00188.x

Dunkel, M., Schmidt, U., Struck, S., Berger, L., Gruening, B., Hossbach, J., Jaeger, I.S., Effmert, U., Piechulla, B., Eriksson, R., Knudsen, J., Preissner, R. (2009). SuperScent-a database of flavors and scents. Nucleic Acids Research., 37(suppl_1), D291-D294. https://doi.org/10.1093/nar/gkn695

EBC 4.5.1 (2004). Extract of malt: Congress mash. In: Analytica EBC (ed.). EBC Analysis Committee-Nürnberg, Hans Carl Getränke Fachverlag, Chap. 4.5.1 
EBC 4.7.1 (2000). Colour of malt. Spectrophotometric method (RM). In: Analytica EBC (ed.). EBC Analysis Committee-Nürnberg, Hans Carl Getränke Fachverlag, Chap. 4.7.1

Fan, W., Xu, Y., \& Zhang, Y. (2007). Characterization of pyrazines in some Chinese liquors and their approximate concentrations. Journal of Agricultural and Food Chemistry, 55(24), 9956-9962. https://doi. org/10.1021/jf071357q

Ferreira, V., Jarauta, I., López, R., Cacho, J. (2003). Quantitative determination of sotolon, maltol and free furaneol in wine by solid-phase extraction and gas chromatography-ion-trap mass spectrometry. Journal of Chromatography A, 1010(1), 95-103. https://doi. org/10.1016/S0021-9673(03)00963-4

Fors, S.M., Nörolov, H. (1987). Lager-type beer made from extruded malt; sensory and chemical analyses. Journal of The Institute of Brewing, 93, 496-500. https://doi.org/10.1002/j.2050-0416.1987.tb04541.x

Forster, C., Narziss, L., Back, W. (1998). Investigations of flavor and flavor stability of dark beers brewed with different kinds of special malts. MBAA Technical Quarterly, 35(2), 73-77.

Harding, R.J., Wren, J.J., Nursten, H.E. (1978). Volatile basic compounds derived from roasted barley. Journal of The Institute of Brewing, 84(1), 41-42. https://doi.org/10.1002/j.2050-0416.1978.tb03836.x

Hérent, M.-F., Collin, S. (1998). Pyrazine and thiazole structural properties and their influence on the recovery of such derivatives in aroma extraction procedures. Journal of Agricultural and Food Chemistry, 46(5), 1975-1980. https://doi.org/10.1021/jf970882u

Ishizaki, S., Tachihara, T., Tamura, H., Yanai, T., Kitahara, T. (2005). Evaluation of odour-active compounds in roasted shrimp (Sergia lucens Hansen) by aroma extract dilution analysis. Flavour and Fragrance Journal, 20(6), 562-566. https://doi.org/10.1002/ffj.1484

Kanzler, C., Haase, P.T. (2019). Melanoidins formed by heterocyclic Maillard reaction intermediates via aldol reaction and Michael addition. Journal of Agricultural and Food Chemistry, 68(1), 332-339. https:// doi.org/10.1021/acs.jafc.9b06258

Korhoňová, M., Hron, K., Klimčíková, D., Müller, L., Bednář, P., Barták, P. (2009). Coffee aroma-Statistical analysis of compositional data. Talanta, 80(2), 710-715. https://doi.org/10.1016/j.talanta.2009.07.054

Mackie, A.E., Slaughter, J.C. (2002). Formation of 4-hydroxyfuranones and their precursors during production of worts and beers. Journal of The Institute of Brewing, 108(3), 336-343. https://doi. org/10.1002/j.2050-0416.2002.tb00558.x

Mahajan, S.S., Goddik, L., Qian, M.C. (2004). Aroma Compounds in Sweet Whey Powder. Journal of Dairy Science, 87(12), 4057-4063. https:// doi.org/10.3168/jds.S0022-0302(04)73547-X

MEBAK, 2.23.6 (2013). Determination of steam-volatile aroma compounds in beer. In: MEBAK Wort, Beer, Beer-based beverages, Freising-Weihenstephan, Germany. ISBN 978-3-9805814-7-9
Miedaner, H. (1986). Wort boiling today - old and new aspects. Journal of The Institute of Brewing, 92(4), 330-335. https://doi. org/10.1002/j.2050-0416.1986.tb04419.x

Nursten, H. E. (2005). The Maillard reaction: chemistry, biochemistry and implications. Royal Society of Chemistry, pp. 214. ISBN 978-085404-964-6, http://dx.doi.org/10.1039/9781847552570

Pickett, J.A., Coates, J., Peppard, T.L., Sharpe, F.R. (1976). Chemical characterization of differences between ales and lagers. Journal of The Institute of Brewing, 82(4), 233-238. https://doi. org/10.1002/j.2050-0416.1976.tb03763.x

Pittet, A.O., Rittersbacher, P., Muralidhara, R. (1970). Flavor properties of compounds related to maltol and isomaltol. Journal of Agricultural and Food Chemistry, 18(5), 929-933. https://doi.org/10.1021/jf60171a044

Pubchem (a) [online]. https://pubchem.ncbi.nlm.nih.gov/compound/2-Acetylpyridine\#section=Computed-Properties [2021-03-25]

Pubchem (b) [online]. https://pubchem.ncbi.nlm.nih.gov/compound $/ 2$-Methylpyridine\#section=Atmospheric-Concentrations [2021-03-25]

Pubchem (c) [online]. https://pubchem.ncbi.nlm.nih.gov/compound/2-Acetylthiazole\#section=Chemical-Vendors [2021-03-25]

Sakuma, S., Kobayashi, K., Tayama, T., Yokoyama, H. (1996). Formation of sweet flavor compounds during fermentation. Journal of the American Society of Brewing Chemists, 54(1), 37-40. https://doi. org/10.1094/ASBCJ-54-0037

Scholtes, C., Nizet, S., Collin, S. (2012). Occurrence of sotolon, abhexon and theaspirane-derived molecules in Gueuze beers. Chemical similarities with 'yellow wines'. Journal of The Institute of Brewing, 118(2), 223-229. https://doi.org/10.1002/jib.34

Shibamoto, T. (1986). Odor threshold of some pyrazines. Journal of Food Science, 51(4), 1098-1099. https://doi. org/10.1111/j.1365-2621.1986.tb11250.x

Van Boekel, M.A.J.S. (1998). Effect of heating on Maillard reactions in milk. Food chemistry, 62(4), 403-414. https://doi.org/10.1016/S03088146(98)00075-2

Viro, M. (1984). Heterocyclic nitrogen compounds in whisky and beer. Chromatographia, 19, 448-451. https://doi.org/10.1007/ BF02687785

Vandecan, S.M.G., Daems, N., Schouppe, N., Saison, D., Delvaux, F.R. (2011) Formation of flavor, color, and reducing power during the production process of dark specialty malts. Journal of the American Society of Brewing Chemists, 69(3), 150-157. https://doi.org/10.1094/ASBCJ-2011-0626-01

Yahya, H., Linforth, R.S.T., Cook, D.J. (2014). Flavour generation during commercial barley and malt roasting operations: A time course study. Food Chemistry, 145, 378-387. https://doi.org/10.1016/j. foodchem.2013.08.046 